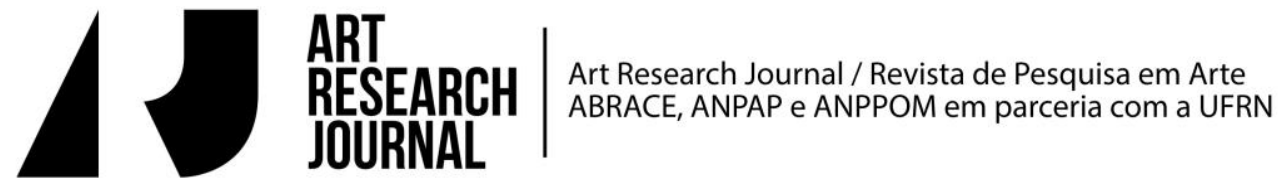

\section{O campo ampliado da gravura: continuidades, rupturas, cruzamentos e contaminações}

\author{
Maria do Carmo de Freitas Veneroso \\ PPGA-UFMG/CNPq
}

Tenho buscado com minhas investigações analisar como a mudança no estatuto da gravura, processada ao longo do século $X X$, e que tem tido continuidade no século $X X I$, tem possibilitado a abordagem das práticas de impressão a partir da perspectiva de um campo ampliado, no qual a gravura dialoga com outras linguagens. A existência deste campo ampliado da gravura traz para esta discussão o conceito da escultura no campo ampliado de Rosalind Krauss. Em texto publicado em 1979 na revista October ${ }^{1}$, Krauss afirma que:

\begin{abstract}
Nos últimos dez anos coisas realmente surpreendentes têm recebido a denominação de escultura: corredores estreitos com monitores de TV ao fundo; grandes fotografias documentando caminhadas campestres; espelhos dispostos em ângulos inusitados em quartos comuns; linhas provisórias traçadas no deserto. Parece que nenhuma dessas tentativas, bastante heterogêneas, poderia reivindicar o direito de explicar a categoria escultura. Isto é, a não ser que o conceito dessa categoria possa se tornar infinitamente maleável (Krauss, 2008, p. 129).
\end{abstract}

Concordo com a autora quando ela pontua que a ampliação do campo que caracteriza o território do pós-modemismo possui dois aspectos implícitos: "um deles diz respeito à prática dos próprios artistas; o outro, à questão do meio de expressão" (Krauss, 2008, p. 136). Com relação à prática individual, é fácil perceber que muitos artistas se viram ocupando, sucessivamente, diferentes lugares dentro do campo ampliado. Krauss aponta que houve uma suspeita por parte da crítica com relação a uma trajetória artística que se move contínua e

$1 \mathrm{O}$ texto $A$ escultura no campo ampliado foi publicado pela primeira vez em português na revista GÁVEA e a versão aqui citada é a sua republicação na Arte \& Ensaios. Rio de Janeiro: EBA, UFRJ, 2008. Ano XV, n¹7, 128-137, 2008. 
desordenadamente além da área da escultura. Segundo a autora isto:

\begin{abstract}
...deriva obviamente da demanda modernista de pureza e separação dos vários meios de expressão (e portanto a especialização necessária de um artista dentro de um determinado meio). Entretanto, o que parece ser eclético sob um ponto de vista, pode ser concebido como rigorosamente lógico de outro. Isto porque, no pós-modernismo, a práxis não é definida em relação a um determinado meio de expressão - escultura - mas sim em relação a operações lógicas dentro de um conjunto de termos culturais para o qual vários meios - fotografia, livros, linhas em parede, espelhos ou escultura propriamente dita possam ser usados (Krauss, 2008, p. 136).
\end{abstract}

Pode-se traçar um paralelo entre aquilo que ocorreu com a escultura em função das mudanças trazidas com o minimalismo, levando à ampliação do seu campo, e o que aconteceu com a gravura, considerando tanto o impacto da pop art sobre a produção dos gravadores, quanto aquele trazido pela arte conceitual, que levou à exploração do uso da linguagem verbal em gravuras e livros de artista impressos, a partir do final dos anos 1960 e início dos anos 1970 . Tudo isto possibilitaria uma utilização mais libertária e experimental dos meios gráficos pelos artistas. Assim, o campo pós-modernista da gravura envolveria uma expansão similar ao da escultura, em torno de um conjunto diferente de termos do binômio arquitetura/paisagem - envolvendo provavelmente os binômios unicidade/reprodutibilidade e ainda alta/baixa cultura.

A troca frequente que tem existido entre as linguagens artísticas faz com que, ao interagirem umas com as outras, elas contribuam para que ocorra uma ruptura com antigos parâmetros que preservavam a autonomia das disciplinas, exigindo assim, novas formas de abordagem. Discutindo a crise da História da Arte, a pesquisadora Maria Lúcia Kern afirma que a arte contemporânea se produz a partir de mudanças substanciais em relação à arte moderna. Segundo a professora "essas mudanças não se enquadram mais nos critérios da historiografia tradicional, de obras originais e eternas, de evolução e progresso, de arte universal monolítica, ou a restrição às categorias, tais como pintura, escultura, gravura e desenho" (Kern, 2005, p. 7). Concordo com a autora, quando ela afirma que:

As vinculações da arte contemporânea com outros campos do saber e das atividades culturais acentuam a crise da História da Arte que até então trabalhava com o conhecimento especializado. Além disso, a instabilidade da arte contemporânea, as polêmicas internas ao seu campo e lançadas para fora do mesmo, bem como a sua constante constituição, dificultam a sua definição (Kern, 2005, p. 7). 
Assim, a arte a partir da segunda metade do século XX tem se encaminhado em direção a um questionamento dos seus conceitos básicos. Buscando novos parâmetros, os artistas experimentam diferentes tendências no sentido de estender o campo das artes para além de uma pura visualidade.

As questões sobre as quais se pretende especular neste texto envolvem, pois, a tendência da gravura atual de ampliar seu campo de atuação. Interessa ainda a este estudo a problematização das relações entre gravura artística e gravura comercial, envolvendo as relações e cruzamentos entre a gravura como ofício e como meio de expressão.

Pode-se considerar que os procedimentos técnicos envolvidos na gravura e na impressão gráfica, de uma maneira geral, aproximam a gravura artística e comercial através de processos de impressão utilizados por artistas e por designers ou publicitários.

As tradicionais fronteiras da arte impressa não são mais tão claras como costumavam ser. Na imaginação popular, a gravura pura deveria ser uma delicada gravura em metal em preto e branco, mas na realidade não há tal coisa como uma gravura pura. Os artistas estão continuamente redefinindo parâmetros (Wye, 1996, p. 7).

Pode-se perceber, por exemplo, que vários artistas contemporâneos têm lançado mão de processos comerciais de impressão. Enquanto esta apropriação de técnicas comerciais aproxima seus trabalhos da publicidade, as mensagens neles veiculadas geralmente subvertem este uso.

Minhas investigações sobre a gravura partem da minha própria experiência como gravadora e também das colocações de autores como Walter Benjamin, que com seu texto "A obra de arte na era da reprodutibilidade técnica" (Benjamin 1994), lança as bases para se discutir as mudanças trazidas com a reprodutibilidade técnica da imagem, em questões como a autoria, o conceito de originalidade e autenticidade, além do anacronismo da gravura.

Ao retomar estas questões no contexto contemporâneo, Georges Didi-Huberman contribui para esta discussão, principalmente com o texto publicado originalmente no catálogo da exposição L'Empreinte, que ocorreu no Beaubourg, em Paris, em 1997 e deu origem ao livro La ressemblance par contact. Archéologie, anachronisme et modernité de l'empreinte (Didi-Huberman 2008), no qual o autor discute a impressão, conceito fundamental para este estudo, de uma forma ampla e abrangente. 
Andreas Huyssen (1987) é outro importante interlocutor, ao trazer a discussão sobre o fim da grande divisão entre arte culta e arte popular, que também alimenta meus questionamentos sobre a gravura atual.

A partir dessas colocações preliminares, este texto busca discutir a gravura no campo ampliado, enfocando especificamente as relações entre gravura artística e comercial, seus cruzamentos e contaminações, tendo como foco o jornal como metáfora da modernidade e da contaminação da arte pela linguagem comercial.

\section{Arte culta $x$ cultura de massa}

Podem ser apontados três momentos de ruptura que afetaram profundamente a gravura, de uma forma particular, e a impressão, num sentido mais amplo: o desenvolvimento da imprensa no ocidente a partir do Renascimento e mais tarde, na modernidade, a invenção e o desenvolvimento da fotografia, seguidos da revolução/proliferação digital, que também vem afetando profundamente a arte e a gravura.

Dentre os momentos de ruptura apontados, o surgimento da fotografia (1826) pode ser considerado determinante para as artes como um todo, e para a gravura em particular, já que a fotografia iria revolucionar as formas de impressão. Se até este momento, marcas, cartazes, mapas e outros impressos comerciais eram impressos em gravura, com o surgimento de novas técnicas de impressão, baseadas na fotografia, eles passam a ser impressos com a utilização de clichês e do off-set. A partir daí as técnicas de gravura começam a tornar-se obsoletas para o uso comercial passando a ser apropriadas pelos artistas, o mesmo ocorrendo com a tipografia, sendo que este é um processo que continua a acontecer dada a constante obsolescência das técnicas de impressão comercial.

No século $X X$, a gravura ampliou seu campo de atuação, passando a dialogar com outras linguagens artísticas, principalmente a partir dos anos 1960, quando houve um verdadeiro renascimento da gravura em países como Estados Unidos e Brasil, entre outros, depois de um relativo retraimento. Pode-se buscar as motivações para este renascimento na ênfase dada aos processos de impressão nesta época, quando houve um grande desenvolvimento dos meios de comunicação de massa e a popularização da imagem gráfica. A eclosão da pop art foi um fator determinante nesta retomada da gravura, em novos termos, com a quebra da Grande Divisão entre arte culta e arte popular. Andreas Huyssen 
explica que o que ele chama de a grande divisão é o tipo de discurso que insiste na distinção categórica entre arte culta e cultura de massa (1987: viii). A quebra desta grande divisão explicaria a contaminação da arte pelos meios de comunicação de massa e vice-versa. Segundo o autor:

...as fronteiras entre arte culta e cultura de massa tornaram-se cada vez mais turvas, e deveríamos começar a ver esse processo como uma oportunidade, em vez de lamentar a perda de qualidade e a falta de vigor. Há várias tentativas bem sucedidas da incorporação de formas da cultura de massa por artistas, em seu trabalho, e certos segmentos da cultura de massa têm, cada vez mais, adotado estratégias da arte culta. Pelo menos, essa é a condição na literatura e nas artes. Já faz algum tempo que artistas e escritores têm vivido e trabalhado além da "Grande Divisão" (Huyssen, 1987, p. ix).

Artistas e poetas contribuíram e continuam a contribuir para o diálogo entre arte culta e cultura de massa, através da incorporação de estratégias que rompem com esta dicotomia entre alta/baixa cultura. Sem dúvida o desenvolvimento e a popularização de novos processos de impressão colaboraram fortemente para que a imagem gráfica inundasse até mesmo o espaço público, na forma de intervenções urbanas. A apropriação de imagens pré-existentes, a colagem, os processos fotográficos, a busca da tridimensionalidade na gravura são alguns dos fatores que colaboram para a expansão do modo de atuação dos gravadores. Tem havido uma nítida aproximação entre impressão, texto e imagem, cujo diálogo pode ser analisado também a partir da origem comum da escrita, do desenho e da impressão, sendo que seus desdobramentos através dos tempos culminaram na sua retomada pelos artistas contemporâneos. Por todos esses fatores mencionados, as fronteiras que definiam a gravura começaram a desfocar.

A mudança operada no estatuto da gravura gerou pelo menos duas tendências igualmente importantes. Enquanto vários gravadores continuaram fiéis às técnicas tradicionais de gravura, outros passaram a estender os seus limites além daqueles usualmente aceitos. As décadas de 1980 e 1990 foram muito propícias para a gravura, em razão da sua liberdade e diversidade e naquele momento:

...enquanto alguns artistas começaram a utilizar o potencial do meio para interagir diretamente com a sociedade através de técnicas comerciais, outros trouxeram o compromisso e a energia de uma nova geração, às técnicas tradicionais praticadas em ateliês profissionais já estabelecidos (Wye, 1996, p. 14-15).

E ainda:

Aqueles cujas estratégias envolviam uma ruptura das barreiras entre arte e vida geralmente procuravam na gravura um meio para alcançar 
um objetivo, e no curso natural do desenvolvimento do seu trabalho, enquanto os gravadores tradicionais eram selecionados para trabalhar nesse meio por editores de gravuras (Wye, 1996, p. 15).

A partir dessa época passou a existir uma convivência entre técnicas tradicionais de gravura e outras menos ortodoxas. Alguns artistas continuaram a abordar a gravura a partir da perspectiva da pintura, uma prática que geralmente leva ao emprego de técnicas tradicionais de impressão. Para outros, cuja arte se fundamenta sobretudo no conceito, a gravura passa a ser um meio usado de forma mais experimental.

\section{Impressão/palavra/imagem}

Nota-se atualmente uma estreita relação entre a palavra e a imagem nas artes, muitas vezes envolvendo procedimentos de impressão. Porém, estas relações existem desde os tempos mais remotos, considerando que a arte pré-histórica pode ser considerada a escrita do homem pré-histórico. Este diálogo teve continuidade até o Renascimento, sendo que com a invenção da imprensa as relações entre a impressão, a palavra e a imagem sofreram abalos e transformações, vindo a se reconciliar a partir do final do século XIX e início do século $\mathrm{XX}$, no trabalho de artistas e poetas, como Stéphane Mallarmé e Pablo Picasso, que passaram a abordar a escrita como imagem, em suas obras.

Percebe-se que a utilização do texto visual por parte dos artistas a partir do século XX está ligada a uma forte tendência das artes naquele século em utilizar fontes e materiais, principalmente impressos, não artísticos. Ela está presente desde o cubismo, nos papiers collés de Pablo Picasso e Georges Braque e nas colagens de Kurt Schwitters, surgindo também na obra de Marcel Duchamp, com seus ready-mades. Na pop art esta tendência foi retomada no trabalho de vários artistas, com destaque para Robert Rauschenberg e Andy Warhol. Se a gravura artística havia trilhado seu caminho sem alterações significativas até a década de 1960, quando as técnicas e imagens gráficas invadiram o mundo artístico, os artistas começaram a associar as técnicas tradicionais da gravura artística com outras baseadas na reprodução fotográfica e outros meios já usados comercialmente. A pop art é um momento especialmente fecundo neste contexto, continuando a trazer inúmeros desdobramentos.

Isto aponta para a contaminação da gravura por processos comerciais de impressão, como o jornal diário, o cartaz de rua e a publicidade, tocando num 
ponto importante: as relações entre gravura artística e gravura comercial. Podese dizer que continua a existir um diálogo entre ambas, e talvez seja possível afirmar que a impureza e a contaminação são características inerentes às atividades gráficas, não fazendo sentido buscar uma pureza dos meios gráficos. Pode-se citar vários exemplos nos quais este diálogo é explorado pelos artistas, agregando significado às obras, como o uso do jornal como suporte ou referência, a impressão lambe-lambe, os stickers, etc.

O jornal pode ser utilizado como uma metáfora da contaminação da gravura: no início, a gravura era utilizada para ilustrar textos e para o desenho de charges, em jornais e revistas, como aquelas impressas em litografia por Honoré Daumier. Mais tarde o jornal passou a ser usado pelos artistas como suporte para impressões e também como um veículo para a veiculação de suas ideias. 0 processo de contaminação da gravura artística por processos comerciais continua, através de outros meios gráficos, como a impressão digital, não fazendo mais sentido tentar preserver uma suposta pureza da gravura, já que este diálogo entre arte e não-arte pode ser estimulante.

Assim, interessa a este estudo o fato da gravura, em termos históricos, ter sido utilizada com finalidades não artísticas, feito parte de circuitos que não são reconhecidos como "de arte". É estimulante pensar que essa espécie de "impureza" da gravura é algo inerente à ela e que não deveria ser ocultado ou superado, mas, pelo contrário, ser explorado e colocado em foco pelo gravador. Ou seja, talvez seja desafiador buscar não a diferenciação entre gravura comercial e gravura artística, mas algo na direção oposta, que questione, coloque em xeque, provoque um curto-circuito na diferenciação, como já vem sendo feito por vários artistas.

\section{O jornal diário como metáfora da modernidade}

Na passagem do século XIX ao XX, paralelamente a um movimento em direção a uma poesia que utiliza, cada vez mais, elementos plásticos em seus trabalhos, ocorria uma situação análoga nas artes plásticas, com os artistas utilizando, cada vez mais, recursos da escrita em suas obras. Pode-se afirmar que a palavra apareceu pela primeira vez no espaço do quadro, de uma maneira mais sistemática e integrada ao discurso plástico, na produção dos pintores cubistas, na década de 1910. As idéias do progresso e da modernidade vão substituir o culto da natureza e a fascinação pela paisagem, presentes na produção pictórica 
do século XIX. Através da apropriação de fragmentos da realidade urbana, com a utilização de material impresso como textos tipográficos, jornais, partituras musicais, embalagens, bilhetes de metrô, os pintores cubistas introduzem a palavra em suas colagens.

Como já foi pontuado, as relações entre a impressão e a escrita são históricas e na contemporaneidade nota-se uma retomada desta vocação da gravura em dialogar com a escrita. Isto tem se dado de várias maneiras: alguns gravadores criam diálogos intertextuais com a literatura, a publicidade aparece muitas vezes sendo subvertida no trabalho de diferentes artistas que trabalham com várias formas de impressão, o texto surge como imagem em uma série de obras, artistas veiculam mensagens políticas através de seus textos visuais, discutindo questões de gênero, raça, etc.

Minha abordagem das relações entre palavra e imagem parte da consideração de que surgiu uma nova maneira de abordar este diálogo a partir do final do século XIX, tanto nas Artes Plásticas quanto na Literatura, reatando antigos vínculos entre a palavra e a imagem. Foi o poeta Stéphane Mallarmé quem chamou a atenção de artistas e poetas para a visualidade da palavra escrita e para a importância da superfície da página, ou seja os brancos ou intervalos, na construção do poema, enquanto Picasso e Braque também exploravam as possibilidades do texto como imagem em suas obras. Assim, a partir das colagens cubistas destes dois artistas, do poema Un coup de dés de Mallarmé e dos Caligramas de Guillaume Apollinaire, surge uma nova visualidade da letra e da página, que irá se estender por todo o século $X X$, tendo continuidade no século XXI, no trabalho de artistas e poetas.

Um fator importante deve ser mencionado, na ênfase dada à visualidade e à materialidade da palavra no poema de Mallarmé e nas colagens de Picasso: ambos usam o jornal impresso como uma referência importante nos seus trabalhos. Apesar do jornal diário ter surgido em Leipzig, na Alemanha, em 1650, foi graças aos avanços nas técnicas de impressão trazidos com a modernidade que ele se popularizou. Também a descoberta no século XIX do potencial comercial do jornalismo como negócio lucrativo, pelos empresários, levou ao surgimento das primeiras publicações parecidas com os diários atuais. Sem dúvida, a popularização do jornal, que fez parte da nova visualidade do periodo, foi determinante no trabalho de poetas e artistas. 
Mallarmé utiliza no seu poema o mesmo tipo de irregularidade tipográfica típica dos jornais: a mistura de diferentes tamanhos de fontes, o uso de combinação de caixa alta, caixa baixa e itálico, e a criação de lay-outs assimétricos e espaços visualmente motivados. Nas colagens de Picasso a referência ao jornal é evidente, uma vez que ele utiliza folhas de jornal impressas como elementos importantes nas mesmas, assim como outros materiais impressos de segunda mão.

A apropriação do jornal e de outros materiais impressos de segunda mão vai ser feita por vários artistas, e esta vertente da impressão terá continuidade pelo século XX e início do século XXI. Yves Klein produz um trabalho marcante em 27 de novembro de 1960, no qual um jornal impresso é usado como veículo para a sua mensagem. Trata-se de Dimanche, le journal d'un seul jour, no qual ele reproduz a emblemática montagem fotográfica em que ele salta no vazio. Nesta época, Klein estava imerso no conceito de imaterialidade, e depois de ter realizado a exposição $O$ vazio, em 1958, na qual deixou a galeria completamente vazia, abordou a levitação com o sentido de atingir a espiritualidade e a liberdade absolutas.

A obra emblemática de Marcel Duchamp, a Caixa Verde (1934), também remete diretamente a duas grandes aquisições da nossa cultura: a imprensa e a fotografia. Dentro desta mesma abordagem, encontra-se o Fluxus, com Fluxus Collective, maleta que traz obras produzidas pelo grupo, incluindo um jornal impresso, e a obra de Arlindo Daibert, Moradas, de 1992, caixa contendo recortes de páginas de livros e outras referências à escrita e à impressão.

Em meados da década de 1990 Antoni Muntadas iniciou a série On Translation, que atualmente é composta por mais de trinta e cinco projetos. Um exemplo, On Translation: Warning, foi lançado em Genebra e inclui intervenções impressas em jornais, cartões postais e adesivos, além de vitrines. O material impresso produzido em massa por Muntadas, trazendo letras brancas em um fundo vermelho, diz "Aviso: Percepção requer envolvimento", e os adesivos que fazem parte desta campanha surgem em locais inesperados. Ao adotar estratégias de meios de comunicação de massa e anunciando e subvertendo-os para as suas próprias mensagens, Muntadas atinge uma população que aprendeu a absorver e interpreter os materiais impressos ao redor. Seu objetivo é romper o entorpecente excesso de informação, proporcionando uma nova visão sobre as formas e meios de manipulação da mídia e chamando para uma participação 
ativa no mundo em geral (Wye; Weitman, 2006, p. 179).

O uso do jornal tem reverberado em outras obras, em diferentes contextos, como a da croata Ivana Keser, mais de vinte e cinco anos mais jovem que Muntadas, e que faz parte de uma geração para a qual práticas alternativas são estratégias comuns. Ela adotou o formato do jornal nas suas próprias obras, depois de ter trabalhado em um pequeno escritório de um jornal, onde aprendeu técnicas básicas do design de lay-out, da escrita editorial e da propaganda. Ela afirma que buscava um tipo de mídia através da qual pudesse expressar suas ideias, uma superfície capaz de receber coisas muito variadas. Até agora Keser concebeu mais de uma dúzia de jornais, entre eles Local-Global (1995) e Local Newspapers (1997), apresentando-os frequentemente em exposições coletivas, onde são oferecidos em pilhas ao público. Neles, a artista inclui comentários sobre questões sociais e políticas, além de reflexões pessoais aleatórias. Seus jornais se tornam colagens visuais e textuais, repletas de associações poéticas entre palavras e imagens (Wye; Weitman, 2006, p. 180).

Felix Gonzalez-Torres também já havia abordado a impressão de um ponto de vista tridimensional, ao utilizar a estratégia de dispor os impressos em pilhas, que lembram os volumes minimalistas. Suas obras, como Untitled (Death by gun) de 1990, são impressas em off-set comercial sobre papel jornal, e através delas o artista discute questões como o múltiplo e a reprodutibilidade técnica levada ao infinito, já que a idéia das pilhas é de que fossem sempre realimentadas com novas provas.

A exploração das relações entre gravura artística e comercial, no Brasil, vem sendo feita por Paulo Bruscky, que vem produzindo desde os anos 1960, dentre outras coisas, aquilo que ele chama de gravura experimental. $O$ artista explica que:

...são gravuras que surgem de coisas que acho na rua, que a tiragem não vai ser mais do que sete ou oito exemplares, em que uso experiências com cores diferentes. São experiências! A xerografia, por exemplo, é gravura, o fax é uma espécie de gravura que venho desenvolvendo (Bruscky, 2011, p. 11).

A multiplicação da imagem perpassa grande parte da produção de Bruscky, incluindo os livros de artista. Ele afirma estar interessado que sua obra "atinja um público grande e não só um público específico que vai a museus e galerias". E completa: "Por isso trabalhei com várias mídias e acho que arte é para circular, por isso fiz diversos projetos/obras dentro do movimento Arte Correio" (Bruscky, 2011: 11-14). Também interessado na ideia da circulação da obra de arte, o 
artista criou o que chama de e-mail arte, uma espécie de trocadilho com Mail Art, considerada ultrapassada com a difusão da internet. O jornal também é adotado como um meio na série Arte Classificada, na qual ele utiliza jornais diários para veicular suas Mensagens. Trata-se de um trabalho em processo, que teve início por volta de 1973, no Jornal do Brasil, e com o qual Bruscky busca "atingir um público grande, inclusive de pessoas alheias à arte [...] Além disso, é uma forma também de registrar uma ideia" (p. 40). Ele explica que é uma volta ao começo do seu trabalho, à sua preocupação com a multiplicidade da sua obra, que, neste caso, "está em cada edição do jornal". Porém, continua, "em 1977 a Polícia Fededal censurou alguns anúncios meus porque diziam que eram mensagens cifradas e passei um periodo proibido de publicar em jornais" (p. 40). Tratava-se de mensagens conceituais: "como colorir as nuvens?" Em um dos trabalhos desta série o artista se apropriou, por exemplo, do bairro da Saudade, em Belo Horizonte: "Saudade não é apenas um bairro em Belo Horizonte, é um sentimento, uma proposta: é arte" (Bruscky, 2011, p. 41).

A impressão de panfletos tem sido utilizada por artistas como Paulo Nazareth, cujo trabalho aponta para a mesma direção citada anteriormente, quando ele expõe os impressos em pilhas sobre mesas, sendo vendidos a preços simbólicos de $R \$ 0,25$ cada um, ou então quando os distribui gratuitamente nas ruas aos transeuntes. Este artista, que também produziu pequenas tiragens de xilogravuras, litografias e fotolitografias, no atelier de gravura, interessa-se pela reprodutibilidade da obra de arte como uma forma de fazê-la circular, motivo pelo qual passou a utilizar processos de reprodução como o off-set comercial de baixo custo, impresso sobre papel jornal, aumentando assim consideravelmente a tiragem de suas obras. Através da P. NAZARETH EDIÇÕES/LTDA ele produz seus impressos, que remetem ao trabalho de Yoko Ono, artista que participou do Fluxus, na forma como ambos utilizam a palavra para propor ações artísticas e políticas. ${ }^{2}$

Apesar de nem todos os últimos trabalhos mostrados serem gravuras stricto sensu, todos eles utilizam a linguagem gráfica e a impressão, de primeira ou de segunda mão. $\mathrm{E}$ todos eles, de alguma maneira, dão sequência aos trabalhos dos artistas e poetas a partir do início do século XX, na forma como abordam a impressão e o diálogo entre palavra e imagem.

2 http://artecontemporanealtda.blogspot.com.br/ 


\section{Considerações finais}

As novas tecnologias têm sido rapidamente incorporadas pela gravura artística e técnicas tradicionais têm sido modificadas e algumas vezes facilitadas pelo xerox e pelo computador, além das impressoras a laser e a jato de tinta. Muitos gravadores têm combinado impressão digital e gravura tradicional, produzindo obras instigantes. A medida que a abrangência cresce, alguns artistas buscam formas de perverter e explorar o potencial desconhecido de métodos mais tradicionais, seja através de superfícies diferentes do papel, trabalhando em uma escala sem precedentes, ou simplesmente por produzir de maneira a ampliar a definição de "gravura".

O aumento das novas mídias - vistas por alguns como uma ameaça para o futuro da gravura - tem simplesmente expandido as opções disponíveis. Assim como a invenção da litografia não deixou a xilogravura e a gravura em metal redundantes, e a fotografia não ditou o fim dos meios gráficos tradicionais, também as tecnologias digitais não substituíram outras tecnologias, mas estenderam opções e possibilidades (Saunders; Miles, 2006, p. 23).

A gravura atravessa, neste início de milênio, uma fase de mudanças e indefinições, que também caracterizam grande parte da arte que vem sendo produzida. Neste contexto, não seria adequado recorrer a conceitos fixos, por tratar-se de um terreno instável e movediço, e por isso mesmo, instigante e desafiador, onde não cabem definições fechadas. Aos poucos, processos de impressão digital estão sendo disponibilizados, para que também possam ser incorporados pelos artistas aos seus trabalhos, fazendo com que a matriz numérica seja usada e valorizada, lado a lado com as matrizes físicas, ampliando ainda mais o campo da gravura.

\section{Referências}

BENJAMIN, Walter. A obra de arte na era de sua reprodutibilidade técnica. In: Magia e técnica, arte e política. São Paulo: Brasiliense, 1994, p.165-196.

BRUSCKY, Paulo. RIBEIRO, Marilia A. (Org.) Paulo Bruscky: depoimento. (Coleção Circuito Atelier). Belo Horizonte: C/Arte, 2011.

DIDI-HUBERMAN, Georges (Org.). L'Empreinte. Paris: [s.n.], 1997. Cat. exp., 19 fev. - 19 mai. 1997, Centre G. Pompidou.

DIDI-HUBERMAN, Georges La ressemblance par contact. Archéologie, anachronisme et modernité de l'empreinte. Paris: Minuit, 2008.

FRANCA, Patrícia (Adapt. Trad.). L'Empreinte Parte I e II. [s/l.: s.n., 2000] Inédito. Do original: DIDI-HUBERMAN, Georges (Org.). L'Empreinte. Paris:[s.n.], 1997. Cat. de exp., 19 fev. - 19 mai. 1997, Centre G. Pompidou.

HUYSSEN, Andreas. After the great divide - Modernism, Mass Culture, Postmodernism. Bloomington and Indianapolis: Indiana University Press, 1987. 
KERN, Maria Lúcia Bastos. Historiografia da arte: revisões e reflexões face à arte contemporânea. Anais do XXIV Colóquio do Comitê Brasileiro de História da Arte. Belo Horizonte: CBHA, 2005.

KOSSOVITCH, Leon; LAUDANNA, Mayra; RESENDE, Ricardo. Gravura: arte brasileira do século XX. SP: Cosac \& Naify: Itaú Cultural, 2000.

KRAUSS, Rosalind. La sculpture dans le champ élargi. In: L'originalité de l'avantgarde et autres mythes modernistes. Paris: Macula, 1993, p. 125-126.

KRAUSS, Rosalind. A escultura no campo ampliado. Arte \& Ensaios. Rio de Janeiro: EBA, UFRJ, 2008. Ano XV, n¹7, 128-137, 2008. Disponível em: www.ppgav.eba.ufrj.br/wp-content/.../ae17 Rosalind Krauss.pdf Acesso em: 12 nov. 2012.

NOYCE, Richard. Printmaking at the edge. 45 artists: 16 countries: a new perspective. London: A \& C Black, 2006.

SAFF, Donald et al. Printmaking: History and Process. New York: Holt Rinehart \& Winston, 1983.

SAUNDERS, Gill; MILES, Rosie. Prints Now: directions and definitions. London: V \& A Publications, 2006.

TÁVORA, Maria Luisa Luz; FERREIRA, Heloisa Pires; CÂMARA, Adamastor. Gravura brasileira hoje: depoimentos. RJ: Oficina de Gravura Sesc Tijuca, 1995. (v. 1 e 2).

VENEROSO, Maria do Carmo de Freitas. Caligrafias e Escrituras: diálogo e intertexto no processo escritural nas artes no século XX. Belo Horizonte: C/Arte, 2012.

VENEROSO, Maria do Carmo de Freitas. A gravura no 'campo ampliado': relações entre palavra e imagem na gravura, gravura e fotografia e gravura tridimensional na contemporaneidade. In: VENEROSO, Maria do Carmo de Freitas; MELENDI, Maria Angelica (Org.). Diálogos entre linguagens Belo Horizonte: C/Arte, 2010.

WYE, Deborah. Thinking Print: Books to Billboards, 1980 - 95. New York: The Museum of Modern Art, 1996.

WYE, Deborah, WEITMAN, Wendy. Eye on Europe. Prints, books, \& multiples/1960 to now. New York: The Museum of Modern Art, 2006. 